This item was submitted to Loughborough's Research Repository by the author.

Items in Figshare are protected by copyright, with all rights reserved, unless otherwise indicated.

\title{
Maximising forward somersault rotation in springboard diving
}

PLEASE CITE THE PUBLISHED VERSION

https://doi.org/10.1016/j.jbiomech.2019.01.033

\section{PUBLISHER}

(c) Elsevier

\section{VERSION}

AM (Accepted Manuscript)

\section{PUBLISHER STATEMENT}

This paper was accepted for publication in the journal Journal of Biomechanics and the definitive published version is available at https://doi.org/10.1016/j.jbiomech.2019.01.033.

\section{LICENCE}

CC BY-NC-ND 4.0

\section{REPOSITORY RECORD}

King, Mark, Pui W. Kong, and Fred Yeadon. 2019. "Maximising Forward Somersault Rotation in Springboard Diving". Loughborough University. https://hdl.handle.net/2134/36767. 


\title{
Maximising forward somersault rotation in springboard diving
}

\author{
${ }^{1}$ M.A. King, ${ }^{2}$ Pui W. Kong and ${ }^{1}$ M.R. Yeadon
}

\author{
${ }^{1}$ School of Sport, Exercise and Health Sciences, Loughborough University, Leicestershire, LE11 3TU, UK \\ ${ }^{2}$ Physical Education \& Sports Science Academic Group, National Institute of Education, Nanyang Technological \\ University, Singapore
}

\begin{abstract}
Performance in the flight phase of springboard diving is limited by the amounts of linear and angular momentum generated during the takeoff phase. A planar 8-segment torquedriven simulation model combined with a springboard model was used to investigate optimum takeoff technique for maximising rotation in forward dives from the one metre springboard. Optimisations were run by varying the torque activation parameters to maximise forward rotation potential (angular momentum $x$ flight time) while allowing for movement constraints, anatomical constraints, and execution variability. With a constraint to ensure realistic board clearance and anatomical constraints to prevent joint hyperextension, the optimised simulation produced $24 \%$ more rotation potential than a simulation matching a $2 \frac{1}{2}$ somersault piked dive. When $2 \mathrm{~ms}$ perturbations to the torque onset timings were included for the ankle, knee and hip torques within the optimisation process, the model was only able to produce $87 \%$ of the rotation potential achieved in the matching simulation. This implies that a pre-planned technique cannot produce a sufficiently good takeoff and that adjustments must be made during takeoff. When the initial onset timings of the torque generators were unperturbed and $10 \mathrm{~ms}$ perturbations were introduced into the torque onset timings in the board recoil phase, the optimisation produced $8 \%$ more rotation potential than the matching simulation. The optimised simulation had more hip flexion and less shoulder extension at takeoff than the matching simulation. This study illustrates the difficulty of including movement variability within performance optimisation when the movement duration is sufficiently long to allow feedback corrections.
\end{abstract}

Keywords: subject-specific, model, angular momentum, rotation potential

\section{INTRODUCTION}

In competitive diving, the score of a dive comprises two parts: the judges' score and the degree of difficulty of the dive performed. Dive height is taken into account when judging a dive and greater height allows more time for rotation and preparation for entry. For a specific dive with fixed rotational requirement and thus degree of difficulty, the diver should seek maximum dive height with sufficient angular momentum to allow extension prior to entry while maintaining a safe distance from the springboard during flight. The degree of difficulty of a dive increases with somersault rotation and therefore it is beneficial to use a dive with a high rotational requirement. The amount of somersault rotation achievable is dependent upon flight time, angular momentum and body configuration. Rotation potential, defined as the product of angular momentum and flight time (Hiley and Yeadon, 2008), normalised to the number of straight somersaults, provides a measure of rotation that is independent of body configuration.

Dive height is associated with a high hurdle giving high vertical downward velocity at touchdown (Sanders and Wilson, 1988), a late arm swing initiated just before the touchdown (Sprigings et al., 1987), a vigorous extension at the hips, knees and ankles to depress the board (Martikkala et al, 1995; Miller and Munro, 1984; Sanders and Wilson, 1988), and minimal joint flexion / hyper-extension that is needed to generate the required angular momentum during the board recoil phase (Sanders and Wilson, 1988). King et al. (2009) used an 8-segment torque-driven simulation model of 
springboard takeoff to maximise peak height in a forward dive pike and found an increase of only $0.04 \mathrm{~m}$ compared to the recorded dive, indicating that the diver used close to optimal takeoff technique.

Angular momentum is built up mainly during the recoil phase of takeoff (Miller, 1981; Miller and Munro, 1985). Hamill et al. (1985) found that platform divers increased forward angular momentum by decreasing the trunk angle to the horizontal and increasing the angular velocity of the trunk at takeoff. In springboard diving, Miller (1974) observed greater board depression, greater hip flexion and shorter contact time as the forward somersaulting requirement increased. Golden (1981) compared forward dives in the pike position with $1 / 2,1 \frac{1}{2}, 21 / 2$, and $31 / 2$ somersaults and found an average $20^{\circ}$ increase in hip flexion and $20^{\circ}$ to $25^{\circ}$ increase in shoulder extension at the last instant of the takeoff with each additional piked somersault. Greater hip flexion increases the moment arm of the board reaction about the mass centre, increasing the resultant torque and angular momentum about the mass centre.

A compromise between gaining height and rotation while maintaining a safe clearance distance has long been recognised. Theoretical calculations (Stroup and Bushnell, 1969) and biomechanical studies (Miller and Munro, 1984; Sanders and Wilson, 1988) have provided evidence that dive height decreases as somersault rotation increases. Figgen (1989) developed a computer simulation model of the flight phase of a dive. Based on theoretical model inputs, it was found that there could be different combinations of vertical velocity, angular momentum and trunk angle at takeoff to perform a good dive. As the forward rotation requirement increases, the diver must increase the amounts of hip flexion and shoulder extension to generate more angular momentum but to what extent the flexion / extension should increase for optimal performance is unclear. Excessive joint flexion / extension would reduce the height reached and reduce the distance travelled in a dive from the forward group.

When a diver aims to perform a given dive in the same manner repeatedly (open loop control), there will be variation in execution and in outcome (Newell and Corcos, 1993). If the movement is of sufficient duration then outcome variability may be controlled using feedforward control (modifying the coordination plan) or feedback (closed loop) control techniques (Jagacinski and Flach, 2003). Execution variability may be incorporated into optimisation with a simulation model by introducing perturbations into each iteration and seeking a solution that maximises the mean or minimum perturbed performance (Wilson et al., 2007; Hiley and Yeadon, 2008). Demonstrating that outcome variability can be reduced sufficiently using feedforward or feedback adjustments is a tractable problem when the outcome is quantised such as the number of twist or somersault revolutions (Yeadon and Hiley, 2017). When the outcome variable to be optimised is a continuous quantity (e.g. rotation potential) such a demonstration may be more problematical since the outcome does not remain fixed.

Torque-driven computer simulation models of springboard diving takeoffs have been used to determine optimum arm and knee timing for maximum somersault rotation (Cheng and Hubbard, 2004; Sprigings and Miller, 2004). Care must be taken, however, to include movement constraints, joint angle constraints, and activation timing variability in such optimisations, if realistic results for maximum rotation potential are to be obtained (Wilson et al., 2007). In addition appropriate limits need to be included for joint strength and for joint torque activation timings as well as accurate estimates of segmental inertias and parameters of elastic elements.

The aim of this study is to optimise springboard diving takeoff technique for maximum forward rotation potential using a torque-driven computer simulation model, allowing for movement constraints, anatomical constraints, and variability of execution. 
The study will also investigate whether adjustments to preplanned takeoff technique are necessary during the contact phase.

\section{METHODS}

A planar 8-segment computer simulation model of a springboard and a diver with torque generators at five joints was used (King et al., 2009; Figure 1) to investigate diving takeoff techniques in the forward dive group. The springboard was modelled as a uniform rod allowing vertical, horizontal and rotational movements (Yeadon et al., 2006a). The FORTRAN code implementing the torque-driven model was generated by the Autolev 3.4TM software package based on Kane's method of formulating equations of motion (Kane and Levinson, 1985). The diver was represented by an 8segment linked system comprising the head, upper arm, lower arm, trunk, thigh, shank and a two-segment foot. Wobbling masses were included within the trunk, thigh and shank segments to represent soft tissue movement during takeoff. The footspringboard interface was modelled using three pairs of parallel and perpendicular damped springs acting at the toes, ball and heel (Yeadon et al., 2006a). There were extensor and flexor torque generators at the ankle, knee, hip and shoulder joints plus a torsional spring at the metatarsal-phalangeal (MTP) joint. There were 18 degrees of freedom in the model: nine defining wobbling mass displacement, two defining foot position, one defining trunk orientation $\theta_{\mathrm{t}}$, five defining joint angles $\left(\theta_{\mathrm{b}}, \theta_{\mathrm{a}}, \theta_{\mathrm{k}}, \theta_{\mathrm{h}}, \theta_{\mathrm{s}}\right.$,), and one defining vertical springboard displacement (Figure 1). The elbow $\left(\theta_{\mathrm{e}}\right)$ and the head $(\theta d)$ angles were driven by joint angle time histories calculated from video recordings of diving performances and defined as a function of time (King et al., 2009).

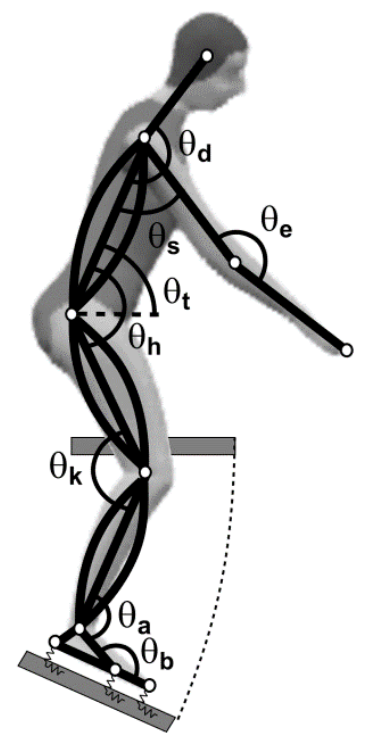

Figure 1. Planar simulation model of a springboard and an 8-segment diver with torque generators acting at the metatarsal-phalangeal, ankle, knee, hip and shoulder joints. $\theta_{\mathrm{d}}$ and $\theta_{\mathrm{e}}$ are taken from recorded joint angle time histories while $\theta_{\mathrm{a}}, \theta_{\mathrm{b}}, \theta_{\mathrm{k}}, \theta_{\mathrm{h}}, \theta_{\mathrm{s}}, \theta_{\mathrm{t}}$ are degrees of freedom calculated during a simulation.

For each torque generator, the torque at time $t$ was calculated as the product of the activation level and the maximum voluntary torque that could be produced at a given joint angle and angular velocity (King et al., 2009). The torque activation level was allowed to ramp up / down between 0 (relaxed) and 1 (fully activated) using a quintic function with zero first and second endpoint derivatives (Yeadon and Hiley, 2000). The extensors ramped up from a low initial level and ramped down towards the 
end of the takeoff (King et al., 2009). In contrast the flexors ramped down from an initial level and then ramped up at the end to prevent hyper-extension. The shoulder flexor was regarded as an extensor in this context since it was responsible for increasing the shoulder joint angle (Figure 1) and the shoulder extensor was regarded as a flexor. Six parameters were required to specify the timing and level of activation for each extensor torque generator (two start times, two ramp durations, two activation levels) and seven parameters were required for each flexor (two start times, two ramp durations, three activation levels) giving a total of 52 parameters (Figure 2). These profiles were chosen as being the simplest that allowed two ramps. The minimum time for the ramping duration was set at $0.1 \mathrm{~s}$ (Duncan and McDonagh, 2000; Freund and Budingen,1978; Bobbert and van Zandwijk, 1999). The maximum initial activation level at touchdown was set at $50 \%$ (Horita et al., 2002). For the torsional spring at the MTP joint the extensor torque was equal to $-k_{s}\left(\theta_{b}-\theta_{\text {flat }}\right) b_{\text {act }}$ where $k_{s}=$ MTP torsional spring stiffness parameter; $\theta_{b}=$ MTP angle (see Figure 1); $\theta_{\text {flat }}=$ MTP angle when the foot is flat and bact $=$ constant activation level (range 0-1; King et al., 2009).

(a)

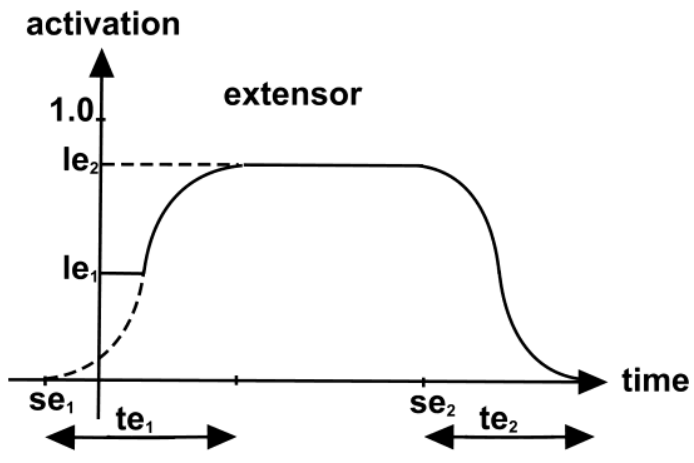

(b)

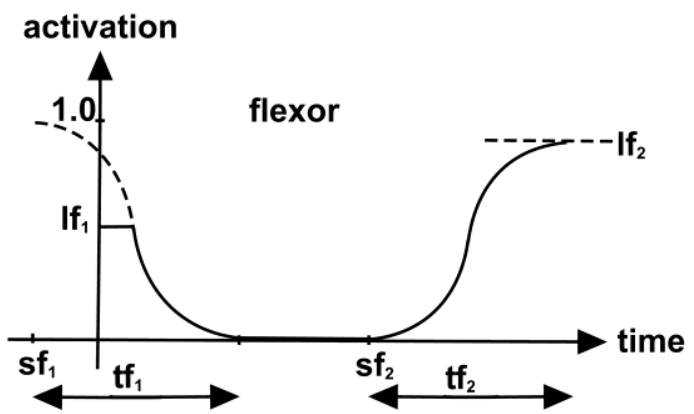

Figure 2. Torque activation profiles of (a) the extensors and (b) the flexors. Each profile requires six parameters: 1) initial starting time (se1, sf1), 2) ramping duration (te1, tf1), 3) final starting time (se2, sf2), 4) ramping duration (te2, tf2), 5) initial activation level (le1, If1) and 6) maximum (for extensor) or final (for flexor) activation level (le2, If2).

The input to the model included: 1) initial conditions at touchdown comprising the springboard vertical displacement and velocity, the diver's foot distance from the end of the board, mass centre velocity, joint angles, trunk orientation and angular velocity, and 2) torque generator activation time histories (the initial mass centre location is defined by the initial foot position and the initial joint angles). The output of the model comprised the time histories of the springboard displacement, angle and angular velocity at each joint, trunk orientation, mass centre velocity and whole-body angular momentum about the mass centre. Takeoff occurred when the board reached its neutral unloaded position.

The simulation model has previously been customised to an elite female diver (mass $=64.1 \mathrm{~kg}$, height $=1.68 \mathrm{~m}$ who had provided informed consent participated in 
this study as approved by the Loughborough University Ethical Advisory Committee) and evaluated by matching two dives by the elite diver; a forward dive pike (101B, FINA, 2017) and forward two and one-half somersault pike (105B, FINA, 2017). Diverspecific segmental inertia, visco-elastic parameters of the wobbling masses and the foot-springboard interface, and diver-specific strength parameters for each torque generator were determined based on isovelocity dynamometer measurements and matching simulations (Yeadon et al., 2006a, b; King et al., 2009). The two simulations matched the performances closely with difference scores of $2.6 \%$ for $101 \mathrm{~B}$ and $3.7 \%$ for 105B based on orientation, configuration, linear and angular momentum at takeoff and contact time (King et al., 2009), indicating that the model was suitable for investigating optimum takeoff techniques.

The simulation model was used to optimise springboard diving takeoff technique for maximum forward rotation. Four optimisations were carried out which maximised an objective function that equalled rotation potential plus the initial orientation minus various constraint penalties. The initial orientation was calculated as a weighted mean of trunk and leg orientations with the trunk angle weighted twice as much as the leg angle. In each optimisation, the initial kinematics were set to be those used in the matching simulation of the 105B dive, and the 53 torque generator activation parameters were varied (52 parameters plus the MTP stiffness parameter) using the Simulated Annealing optimisation algorithm (Corana et al., 1987). In all optimisations penalties were used to ensure the board clearance was realistic (board clearance distance was defined as the horizontal distance between the end of the springboard and the diver's mass centre when the mass centre had descended to board level during flight). The minimum board clearance was set at $1.00 \mathrm{~m}$ and the maximum was set at the actual board clearance in the recorded performance of $105 \mathrm{~B}(1.59 \mathrm{~m})$.

Optimisation 1 was carried out with only the board clearance constraint. In optimisation 2 joint angles were constrained to lie within anatomical limits both at takeoff and during the first $100 \mathrm{~ms}$ of flight to prevent joint hyper-extension. In optimisations 3 and 4 perturbations to the joint torque generator onset activation timings for the ankle, knee and hip were incorporated into the optimisation process. For a given set of activation parameters eight combinations of perturbations to the onset timings of ankle, knee and hip torques were used giving nine simulations in total for a given set of parameters (Table 1) and the objective function score was given the lowest rotational potential score from the nine simulations minus board clearance and joint angle constraint penalties. In optimisation 3 the onset timings for the initial ramp of each torque generator were varied by firstly $1 \mathrm{~ms}$ and then the optimisation was repeated increasing the perturbation size in steps of $1 \mathrm{~ms}$ until $10 \mathrm{~ms}$ was reached or until the optimisation failed to produce as much rotation potential as the matching simulation. This was done to investigate whether a preplanned takeoff technique could be successful. In optimisation 4 the onset timings for the second ramp of each torque generator (mean $0.22 \mathrm{~s}$, range 0.10 to $0.29 \mathrm{~s}$ ) were varied by $10 \mathrm{~ms}$, primarily affecting the board recoil phase, in order to investigate whether a feedforward technique during the board recoil phase could be successful. The optimised simulation was subsequently subjected to $10 \mathrm{~ms}$ perturbations to the onset timings of the first ramps (mean $-0.04 \mathrm{~s}$, range -0.09 to $0.04 \mathrm{~s}$ ) to determine the effect on the system state at maximum depression. No penalties were incurred in any of the optimised solutions. 


\begin{tabular}{cccc}
\hline perturbation & ankle & knee & hip \\
\hline 1 & 0 & 0 & 0 \\
2 & $-x$ & $-x$ & $-x$ \\
3 & $-x$ & $-x$ & $+x$ \\
4 & $-x$ & $+x$ & $+x$ \\
5 & $-x$ & $+x$ & $-x$ \\
6 & $+x$ & $-x$ & $-x$ \\
7 & $+x$ & $-x$ & $+x$ \\
8 & $+x$ & $+x$ & $+x$ \\
9 & $+x$ & $+x$ & $-x$ \\
\hline
\end{tabular}

For each optimised takeoff simulation the flight phase performance was simulated using an angle-driven simulation model of aerial movement (Yeadon et al., 1990) based on the takeoff characteristics of the simulation comprising body orientation and configuration, linear and angular momenta, together with joint angle time histories obtained from the video recordings of 105B. The simulated takeoff configuration was merged into the flight configuration of the performance over the first $100 \mathrm{~ms}$ of flight using a quintic function (Yeadon and Hiley, 2000) and the flight phase was adjusted to produce a good entry configuration and orientation.

\section{RESULTS}

The matching simulation (Figure $3 b$ ) had a rotation potential of 1.09 straight somersaults (ss). In optimisation 1 a theoretical rotation potential of 1.72 ss was obtained but with an unrealistic knee angle of $220^{\circ}$ at takeoff. In optimisation 2 (Figure $3 c$ ) which had penalties to avoid violation of anatomical joint constraints, 1.35 ss were produced. In optimisation 3 which coped with $2 \mathrm{~ms}$ perturbations, a mean rotation potential of only $0.95 \mathrm{ss}$ was produced (range $0.91-1.01 \mathrm{ss}$ ), and this was lower than that of the matching simulation. In optimisation 4 in which the first ramps of the leg torque activations were unperturbed and $10 \mathrm{~ms}$ perturbations were introduced into the onset timings of the second ramp activations (joint deceleration phase), a mean rotation potential of $1.18 \mathrm{ss}$ was obtained (range $1.12-1.26 \mathrm{ss}$ ). Figure $3 \mathrm{~d}$ depicts a perturbation resulting in a simulation with a rotation potential of $1.19 \mathrm{ss}$ in which body configuration in the last part of flight has been adjusted to produce more body extension and better orientation at entry than in the matching simulation (Figure 3b).

The technique used in optimisation 4 differed from that of the matching simulation primarily during the board recoil phase, during which the majority of the angular momentum was generated (Figure 4), with greater hip flexion and a more open shoulder angle at takeoff (Figure 5). When the onset timings of the first ramps of the activation profiles of the joint torque generators in the optimised simulation were perturbed by $10 \mathrm{~ms}$ the root mean square deviations of mass centre horizontal location, mass centre velocity and angular momentum from the values in optimisation 4 at the lowest point were $0.020 \mathrm{~m}, 0.25 \mathrm{~ms}^{-1}$ and $0.17 \mathrm{ss}^{-1} \mathrm{~s}^{-1}$ respectively. The values for horizontal velocity and angular momentum in the optimised simulation were $0.91 \mathrm{~ms}^{-1}$

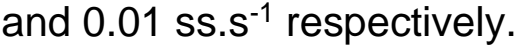


a.

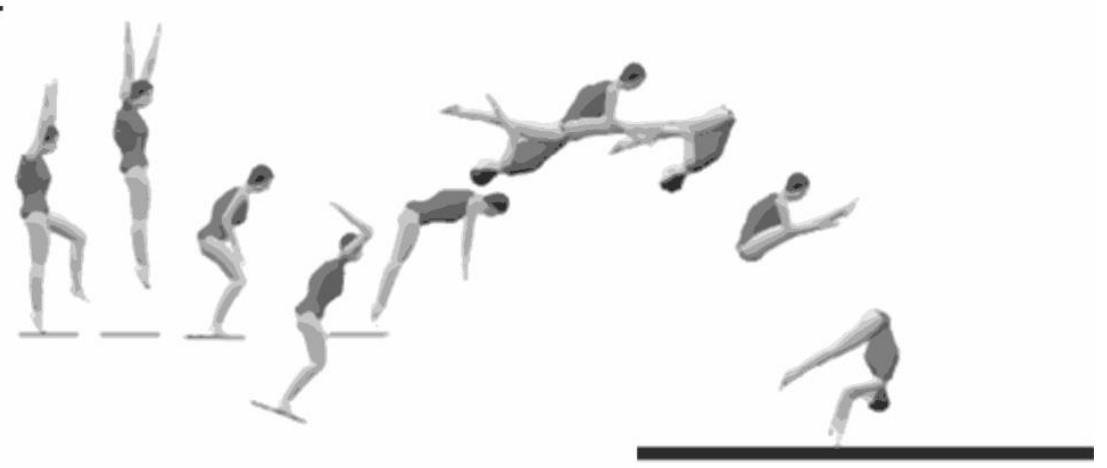

b.

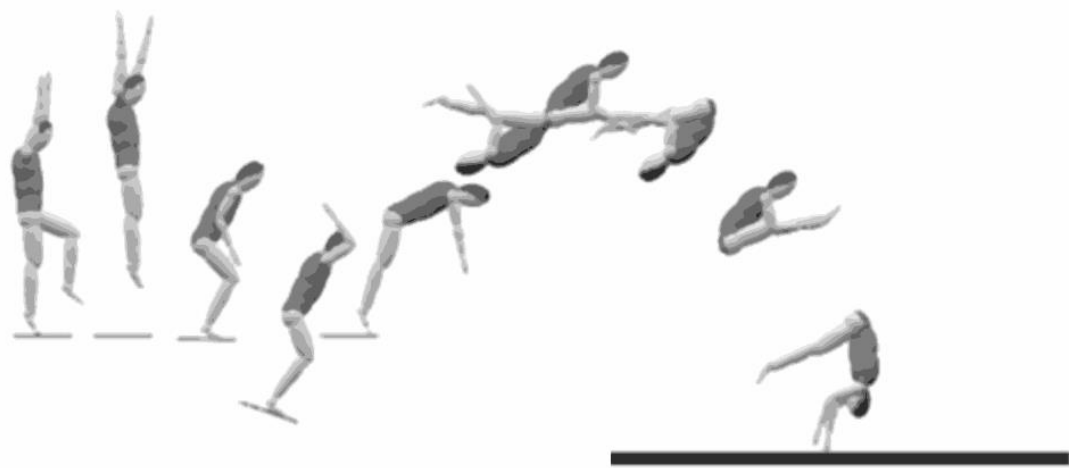

c.

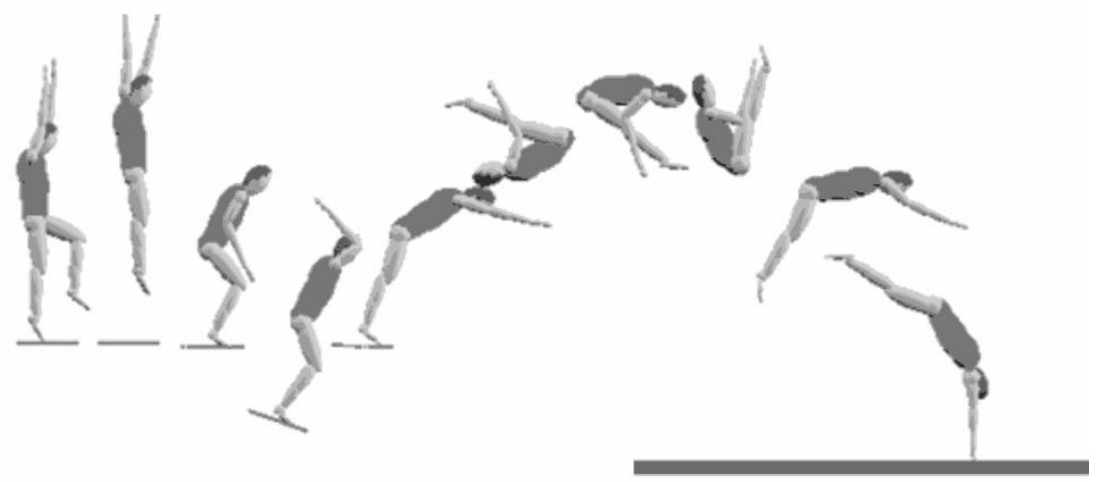

d.

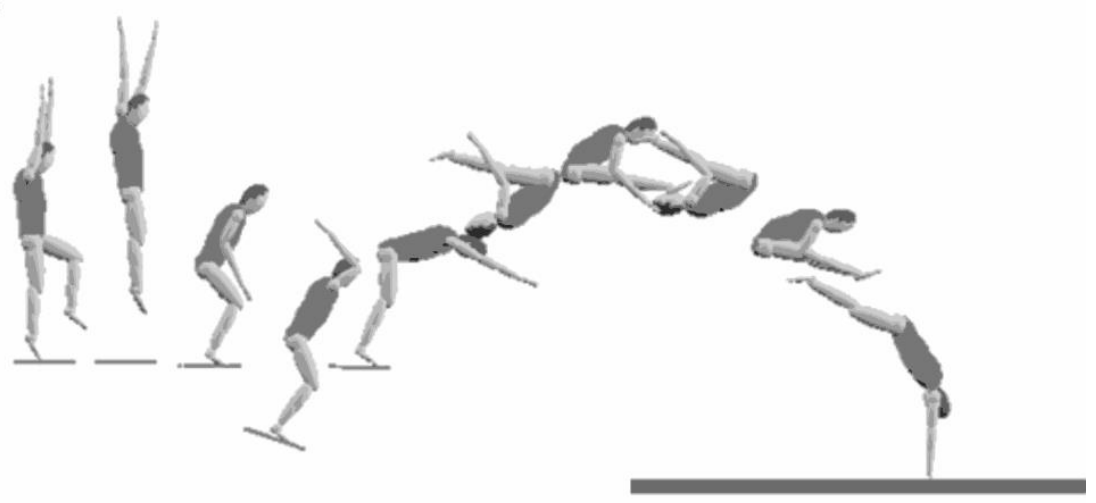

Figure 3. Graphics sequences of (a) recorded dive, (b) matching simulation (rotational potential = 1.09 ss), (c) optimisation 2 (rotation potential = $1.35 \mathrm{ss}$ ), (d) optimisation 4 (rotation potential = $1.19 \mathrm{ss}$ ). Note that (a) and (b) have the same configurations and very similar orientations since simulation (b) aims to match the recorded performance (a). The flight phase differences of (c) and (d) from (a) and (b) can be seen clearly in the last three of four graphics of each sequence. The contact phase differences can only be seen in the fifth graphic at takeoff since the first three graphics (the hurdle step) are all identical and the fourth graphic (lowest point) are all similar. 


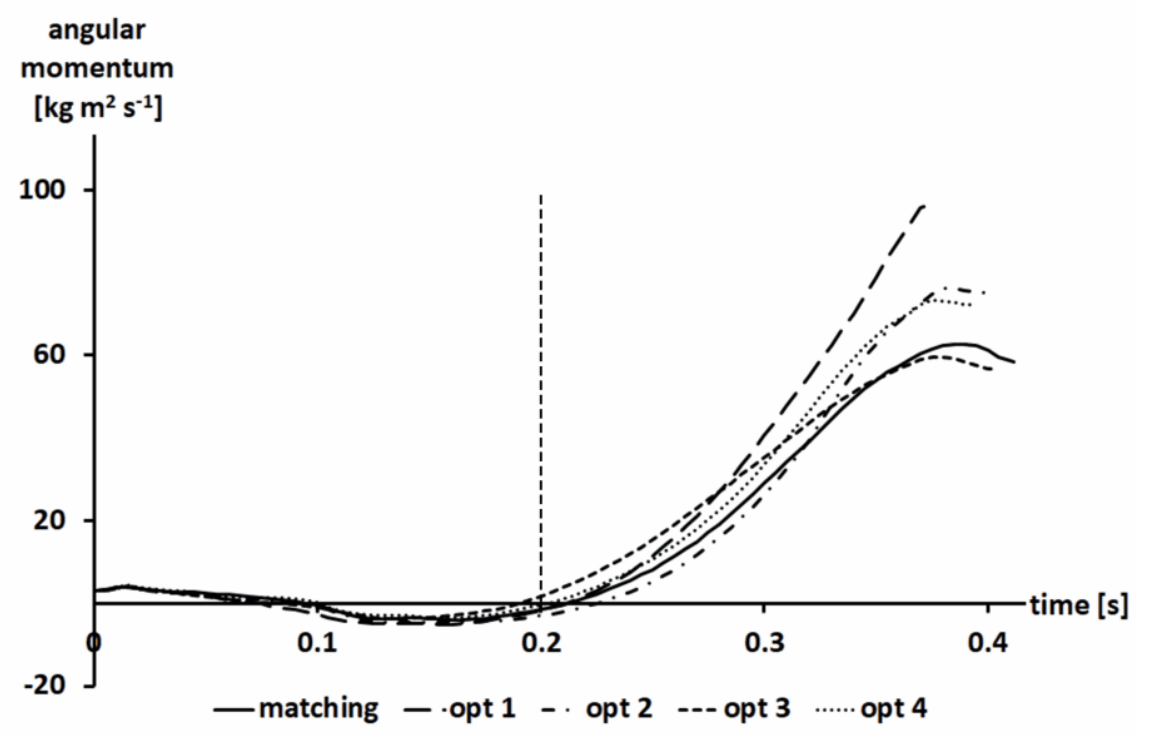

Figure 4. Time history of the angular momentum development during the board contact phase for (a) matching simulation, (b) optimisation 1, (c) optimisation 2, (d) optimisation 3, (e) optimisation 4. Vertical dashed line denotes time of maximum board depression.
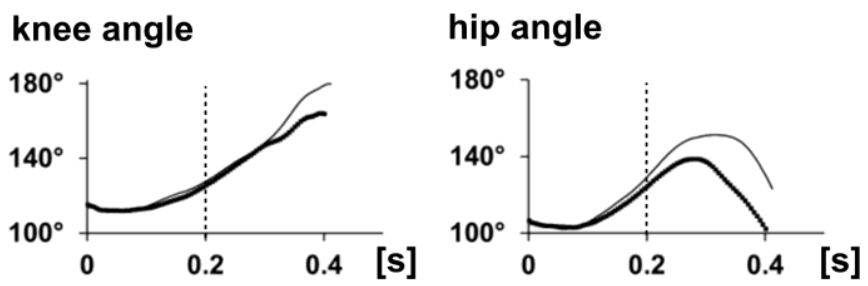

shoulder angle

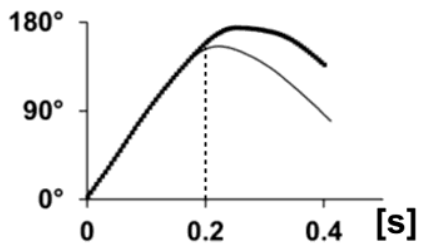

trunk orientation

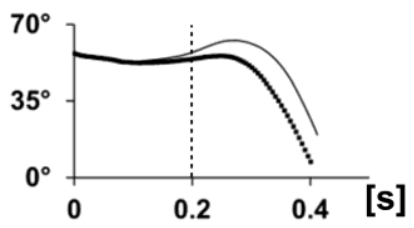

Figure 5. Configuration and orientation angle time histories for the matching simulation (grey) and optimisation 4 (black). Vertical dashed line denotes time of maximum board depression.

\section{DISCUSSION}

The aims of this research study were to optimise springboard diving takeoff technique for maximum forward rotation potential using a torque-driven computer simulation model, allowing for movement constraints, anatomical constraints, and variability of execution, and to investigate whether adjustments to preplanned takeoff technique are needed during the contact phase. The failure of optimisation 3 to cope with timing perturbations throughout the whole of the takeoff phase implies that actual performances must use feedback or feedforward control adjustments during takeoff to compensate for the effects of such execution variability. The results of optimisation 4 indicate that an improvement can be made to the rotation potential achieved in the recorded performance (Figure 3a, d).

Incorporating various constraints into the optimisation process produced quite different results, as found in Wilson et al. (2007), and showed the importance of 
considering all relevant aspects if realistic optimisation is to be achieved. In optimisation 1, when only movement constraints were imposed (distance travelled in flight), 1.72 straight somersaults of rotation potential were obtained which was $58 \%$ greater than the $1.09 \mathrm{ss}$ in the matching simulation although the knee angle at takeoff was beyond anatomical range. In optimisation 2 , in which anatomical constraints were also imposed, 1.35 ss were produced which was an unrealistic $24 \%$ more than in the matching simulation. In optimisation 3 , in which perturbations were introduced to the torque activations throughout takeoff, it was not possible to produce sufficient rotation potential for a forward $2 \frac{1}{2}$ somersault pike dive. In optimisation 4 , in which $10 \mathrm{~ms}$ perturbations were introduced into the onset timings of the second set of activation ramps, the mean rotation potential was 1.18 ss (range $1.12-1.26$ ss) which was a credible $8 \%$ more than in the matching simulation.

The takeoff technique in optimisation 4 was similar to that of the matching simulation during the board depression phase with most changes occurring during the recoil phase (Figures $2 \mathrm{~b}, 2 \mathrm{~d}$ ). This is consistent with the findings of experimental studies that angular momentum is built up (Figure 4) mainly during the recoil phase of the takeoff (Miller and Munro, 1985). The optimised takeoff technique was characterised by greater hip flexion and smaller shoulder flexion at takeoff in comparison with the matched simulation. This technique required small changes in joint torques but all torques necessarily lay within the diver's strength capabilities represented by the maximum voluntary torque / angle / angular velocity relationships. The more open shoulder angle in the optimised technique helps to generate greater angular momentum as the hips are flexed. The greater arm movement in the matching simulation may have been motivated by a desire to reach the required arm position in the pike earlier in flight. This has the advantage of reaching maximum somersault velocity earlier but this is offset by the cost of having lower angular momentum at takeoff. In optimisation 4 only the torque activation timings were varied while all the initial conditions were kept the same as those in the matching simulation. It may be expected that greater rotation potential could be achieved if the initial conditions at touchdown were also optimised, for example using a higher initial vertical downward velocity at touchdown.

In optimisation 4 in which the start times of the second ramps of the activation profiles were perturbed by $10 \mathrm{~ms}$, the propagated variability (SD) in the rotation potential was 0.05 straight somersaults. This variability value is likely to be an underestimate of that which would occur in actual performances since no allowance has been included for variability in touchdown conditions. In Sayyah et al. (2018) 15 performances of forward $2 \frac{1}{2}$ somersault pike dives by an elite diver had a rotation potential of 1.15 straight somersaults with a standard deviation of $0.03 \mathrm{ss}$. The difference in variability could be due to the diver having timing precision better than 10 ms. Hiley et al. (2013) found hip joint precision timings for four elite gymnasts ranging from $4 \mathrm{~ms}$ to $10 \mathrm{~ms}$. Alternatively the elite diver could have made adjustments during takeoff to compensate for perturbations occurring beyond the time of maximum board depression $(0.20 \mathrm{~s})$. Whether the diver makes just a single change to the planned activations during the contact time of $0.4 \mathrm{~s}$ is unknown. In the flight phase of the $2 \frac{1}{2}$ somersault pike dive Sayyah et al. (2018) found that the diver adjusted the time for extending from the pike and subsequently adjusted the timing of the final arm movement and also the pike angle at entry. These three sequential adjustments were made over a period of $0.6 \mathrm{~s}$ and the latter two were based on the body orientation at the time of the previous adjustment. It is therefore conceivable that more than one adjustment could be made in the takeoff duration of $0.4 \mathrm{~s}$. 
It is likely that the diver plans the contact phase of $0.4 \mathrm{~s}$ duration in advance (Miall and Wolpert, 1996) either as open loop control (fixed plan) or using feedforward control (estimating touchdown conditions during the hurdle flight). During the period from touchdown until maximum board depression or shortly thereafter, the diver may evaluate the planned movement in relation to the current performance (Wolpert, 1997) using information related to the velocity and angular velocity of the diver. If there is a discrepancy between the planned performance and the current state, the pre-planned movements are then adapted (feedforward control or feedback control) so that the diver changes the timing or amplitude of the joint activations. For feedforward control there will be a delay of around $0.2 \mathrm{~s}$ before the modification is effected (Henry and Harrison,1961; Gao and Zelaznik, 1991) and so adjustments are likely to be apparent in the board recoil phase. The effect of first ramp perturbations on the lowest point values of horizontal location, mass centre velocity and angular momentum were relatively large. Since the mass centre horizontal location at the lowest point will affect the moment arm of the reaction force from the springboard during the board recoil phase (and thereby the angular momentum generated), some adjustment may be made during the board depression phase using feedback mechanisms as in the control of standing balance since the feedback time delay is around $0.1 \mathrm{~s}$ (Blenkinsop et al., 2017).

This study has shown that the optimisation of movements with durations greater than the feedback delay time is problematical. On the one hand optimised technique should be robust to the inherent execution timing variations. On the other hand, determining an optimised fixed technique is inappropriate when feedforward or feedback correction is used during the takeoff in actual performances. In determining the limits of twisting somersaults in trampolining and diving, Yeadon and Hiley (2017, 2018) determined how much room for variation there was in an optimum solution using the possible range of arm abduction during the twisting phase. In this investigation the problem of having sufficient flexibility to keep an optimised solution on track has been resolved to some extent by restricting timing perturbations to the second half of takeoff. Whether a more general solution to the problem is possible by incorporating a control model into the optimisation process to cope with the effects of timing variability remains to be seen.

Acknowledgment: This study was supported by the International Society of Biomechanics under the Matching Dissertation Grant Program.

\section{REFERENCES}

Blenkinsop, G.M., Pain, M.T.G., Hiley, M.J., 2017. Balance control strategies during perturbed and unperturbed balance in standing and handstand. Royal Society Open Science 4, 161018.

Bobbert, M.F., van Zandwijk, J.P., 1999. Dynamics of force and muscle stimulation in human vertical jumping. Medicine and Science in Sports and Exercise 31, 303-310.

Cheng, K.B., Hubbard, M., 2004. Optimal jumping strategies from compliant surfaces: a simple model of springboard standing jumps. Human Movement Science 23, 3548.

Corana, A., Marchesi, M., Martini, C., Ridella, S., 1987. Minimising multimodal functions of continuous variables with the "simulated annealing" algorithm. ACM Transactions on Mathematical Software 13, 262-280. 
Duncan, A., McDonagh, M.J., 2000. Stretch reflex distinguished from pre-programmed muscle activations following landing impacts in man. Journal of Physiology $526 \mathrm{Pt}$ 2, 457-468.

Figgen, M., 1989. Computer simulation of the two-dimensional flight phase of an athlete. In Proceedings of the XII International Congress of Biomechanics, Abstract 274. University of California, Los Angeles.

FINA (Fédération de Natation Internationale), 2017. FINA Diving Rules. https://www.fina.org/sites/default/files/2017-2021_diving_12092017_ok.pdf

Freund, H.J., Budingen, H.J., 1978. The relationship between speed and amplitude of the fastest voluntary contractions of human arm muscles. Experimental Brain Research 31, 1-12.

Gao, L., Zelaznik, H.N., 1991. The modification of an already-prgrammed response: A new interpretation of Henry and Harrison (1961), Journal of Motor Behaviour 23, 221-223.

Golden, D., 1981. Kinematics of increasing rotation in springboard diving. In Proceedings of the United States Diving Sports Seminar, pp. 55-81. Snowbird, Utah.

Hamill, J., Golden, D.M., Ricard, M.D., Williams, M.A., 1985. Dynamics of selected tower dive takeoffs. In: Terauds, J., Barham, J. (Eds.), Biomechanics in Sports II. Academic Publishers, Del Mar, pp. 200-207.

Henry, F.M., Harrison, J.S., 1961. Refractoriness of a fast movement. Perceptual and Motor Skills 13, 351-354.

Hiley, M.J., Yeadon, M.R., 2008. Optimisation of high bar circling technique for consistent performance of a triple piked somersault dismount. Journal of Biomechanics 41, 1730-1735.

Hiley, M.J., Zuevsky, V., Yeadon, M.R., 2013. Is skilled technique characterised by high or low variability - An analysis of high bar giant circles? Human Movement Science 32, 171-180.

Horita, T., Komi, P.V., Nicol, C., Kyrolainen, H., 2002. Interaction between pre-landing activities and stiffness regulation of the knee joint musculoskeletal system in the drop jump: implications to performance. European Journal of Applied Physiology 88, 76-84.

Jagacinski, R.J., Flach, J.M., 2003. Control theory for humans: Quantitative approaches to modeling performance. Mahwah, NJ: Lawrence Erlbaum Associates, (Chapters 2, 20).

Kane, T.R., Levinson, D.A., 1985. Dynamics: Theory and implementations. McGrawHill, New York.

King, M.A., Kong, P.W., Yeadon, M.R., 2009. Determining effective subject-specific strength levels for forward dives using computer simulations of recorded performances. Journal of Biomechanics 42, 2672-2677.

Martikkala, V., Oksa, J., Viitasalo, J.T., Luhtanen, P., 1995. Evaluated muscular work in diving springboard takeoff. In Proceedings of the XV Congress of the International Society of Biomechanics, pp. 590-591. University of Jyvalskyla, Jyvaskyla.

Miall, R.C., Wolpert, D.M., 1996. Forward models for physiological motor control. Neural Networks, 9, 1265-1279.

Miller D.I., 1974. A comparative analysis of the take-off employed in springboard dives from the forward and reverse groups. In: Nelson R.C., Morehouse C.A. (Eds), Biomechanics IV. International Series on Sport Sciences. Palgrave, London, pp. 223-228. 
Miller, D.I., 1981. Total body momentum considerations during springboard diving takeoffs. In Proceedings of the United States Diving Sports Sciences Seminar, pp. 83-108. Snowbird, Utah.

Miller, D.I., Munro, C.F., 1984. Body segment contributions to height achieved during the flight of a springboard dive. Medicine and Science in Sports and Exercise 16, 234-242.

Miller, D.I., Munro, C.F., 1985. Greg Louganis' springboard takeoff: II. Linear and angular momentum considerations. International Journal of Sport Biomechanics 1, 288-307.

Newell, K.M., Corcos, D.M., 1993. Issues in variability and motor control. In K. M. Newell \& D.M. Corcos (Eds.), Variability and motor control. Champaign, IL: Human Kinetics.

Sanders, R.H., Wilson, B.D., 1988. Factors contributing to maximum height of dives after takeoff from the $3 \mathrm{M}$ springboard. International Journal of Sport Biomechanics 4, 231-259.

Sayyah, M., Hiley, M.J., King, M.A., Yeadon, M.R., 2018. Functional variability in the flight phase of one metre springboard forward dives. Human Movement Science 59, 234-243.

Sprigings, E.J., Paquette, S.E., Watson, L.G., 1987. Consistency of the relative vertical acceleration patterns of a diver's armswing. Journal of Human Movement Studies 13, 75-84.

Sprigings, E., Miller, D.I., 2004. Optimal knee extension timing in springboard and platform dives from the reverse group. Journal of Applied Biomechanics 20, 275290.

Stroup, F., Bushnell, D.L., 1969. Rotation, translation, and trajectory in diving. Research Quarterly 40, 812-817.

Wilson, C., Yeadon, M.R., King, M.A., 2007. Considerations that affect optimised simulation in a running jump for height. Journal of Biomechanics 40, 3155-3161.

Wolpert, D.M., 1997. Computational approaches to motor control. Trends in Cognitive Sciences, 1, 209-216.

Yeadon, M.R., Atha, J., Hales, F.D., 1990. The simulation of aerial movement - IV. A computer simulation model. Journal of Biomechanics 23, 85-89.

Yeadon, M.R., Hiley, M.J., 2000. The mechanics of the backward giant circle on the high bar. Human Movement Science 19, 153-173.

Yeadon, M.R., Hiley, M.R., 2017. Twist limits for late twisting double somersaults on trampoline. Journal of Biomechanics 58, 174-178.

Yeadon, M.R., Hiley, M.R., 2018. The limits of aerial techniques for producing twist in forward 11/2 somersault dives. Human Movement Science 58, 97-107.

Yeadon. M.R., King, M.A., Wilson, C., 2006b. Modelling the maximum voluntary joint torque / angular velocity relationship in human movement. Journal of Biomechanics 39, 476-482.

Yeadon, M.R., Kong, P.W., King, M.A., 2006a. Parameter determination for a computer simulation model of a diver and a springboard. Journal of Applied Biomechanics 22, 167-176. 